\title{
12 Haftalık Hentbol Teknik ve Kuvvet Antrenmanlarının Atış ve Güç Performansı Üzerindeki Etkilerinin Değerlendirilmesi*
}

\author{
Evaluation of the Effects of 12-Week Handlball Technical and Strength Training \\ On Shooting and Power Performance
}

\section{ORİJINAL ARAŞTIRMA/ \\ ORIGINAL RESEARCH}

\section{Oğuzhan PİLÇA ${ }^{\mathbf{1}}$,}

Muammer ALTUN ${ }^{2 \dagger}$

${ }^{1}$ Hentbol Antrenörü, Manisa

https://orcid.org/0000/0001/5727/8474

${ }^{2}$ Manisa Celal Bayar Üniversitesi Spor Bilimleri Fakültesi, Manisa https://orcid.org/0000/0003/2510/5944

\begin{abstract}
Öz
Hentbolda kuvvet antrenmanının performans arttırıcı etkilerini destekleyen çok sayıda çalışma bulunmasına karşın, teknik antrenmanın etkisini gösteren kanıt yoktur. Bu çalışmanın amacı, hentbol teknik ve kuvvet antrenmanlarının $9 \mathrm{~m}$ atış isabeti ve güç performansı üzerindeki etkilerini karşılaştırmaktı. Çalışmaya 19-24 yaş arasında 30 sağlıklı erkek hentbol oyuncusu gönüllü olarak katıldı. Ön testte dikey sıçrama, $20 \mathrm{~m}$ sürat koşusu, sağlık topu atma, 30 sn şınav, 30 sn mekik ve $9 \mathrm{~m}$ kale atışı değerlendirildi. Sporcular, ön-test performanslarına göre sayıları ve özellikleri eşit olan iki gruba ayrıldı. 12 hafta boyunca bir grup teknik antrenman, diğer grup kuvvet antrenmanı yaptı. Antrenman programlarının bitiminden 2 gün sonra aynı testler son test olarak tekrar edildi. Antrenman programı sonrasında teknik grup $9 \mathrm{~m}$ isabet, dikey sıçrama ve $20 \mathrm{~m}$ süratte anlamlı gelişme gösterdi $(\mathrm{p}<0.05)$. Diğer yandan kuvvet antrenmanı grubu, şınav $(\mathrm{p}<0.05)$, mekik ve sağlık topu firlatmada $(\mathrm{p}<0.01)$ anlamlı gelişme gösterdi. Sonuç olarak, teknik antrenmanların hentbol oyuncularının hızlanmasını, dikey sıçrama kuvvetini ve atış isabetlerini arttırması nedeniyle antrenman programlarında teknik antrenmanlara daha fazla önem verilmesi gerektiği söylenebilir.
\end{abstract}

Anahtar Kelimeler: Teknik Antrenman, Kuvvet Antrenmanı, Şut İsabeti, Güç Gelişimi.

\begin{abstract}
Although there are many studies supporting the performance-enhancing effects of strength training on handball, there is no evidence of the impact of technical training. The aim of this study was to compare the effects of handball technical and strength training on $9 \mathrm{~m}$ shots and power performance. Thirty healthy male handball players aged between 19-24 participated in the study voluntarily. In the pre-test, a vertical jump, a 20 $\mathrm{m}$ sprint, a medicine ball throwing, 30 -sec push-ups, 30-sec sit-ups, and a $9 \mathrm{~m}$ goal shot were assessed. The athletes were divided into two groups whose numbers and characteristics were equal based on their pre-test performance. For 12 weeks, one group performed technical training and the other group strength training. Two days after the end of training programs, the same tests were repeated as post-tests. After the training programs, the technical group demonstrated a significant improvement in $9 \mathrm{~m}$ shot precision, vertical jump and $20 \mathrm{~m}$ sprint $(\mathrm{p}<0.05)$. On the other hand, the strength training group showed significant improvement at the push-ups $(\mathrm{p}<0.05)$, sit-ups and medicine ball throwing $(\mathrm{p}<0.01)$. In conclusion, it can be said that in training program plans, technical training should be given more importance because it increases handball players' acceleration, vertical jump strength, and shooting accuracy.
\end{abstract}

Keywords: Technical Training, Strength Training, Shooting Accuracy, Power Development.

\footnotetext{
* Bu çalışma, Oğuzhan PİLÇA’nın DEU. HSI.MSc-2014970031 kodu ile kabul edilen "19-24 yaş arası erkek hentbolcularda farklı türde yapılan antrenmanların atış isabet oranları üzerine etkisi” isimli Dokuz Eylül Üniversitesi Sağlık Bilimleri Enstitüsü Beden Eğitimi ve Spor Anabilim Dalı Hareket ve Antrenman Bilimi Yüksek Lisans tezinden türetilmiştir. Ayrıca bu çalışma 23 - 26 Kasım 2017 tarihlerinde, Manisa'da yapılan Uluslararası Dünya Spor Bilimleri Araştırmaları Kongresinde sözel bildiri olarak sunulmuştur.

† Sorumlu yazar: Muammer ALTUN, Dr. Öğr. Üyesi, E-posta: muammer-altun@ hotmail.com
} 


\section{GİRIŞ}

Hentbol koşunun, sıçramanın, sprint atmanın, atmanın, isabetin, engellemenin ve itmenin önemli olduğu güçlü bir temas sporudur (Gorostiaga, Granados, Ibanez, Gonzalez-Badillo, ve Izquierdo, 2006). Yıllar içerisinde performansların daha üst düzeylere ulaşabilmesi için daha yeni ve modern antrenman metotları geliştirilmiş ve kullanılmaya başlanmıştır (Ürer ve Kılınç, 2014). Özellikle yüksek düzeyde performansa ulaşmak için teknik, taktik, kondisyon ve koordinasyon gibi faktörlerin geliştirilmesi gereklidir (Baumberger, 1992). Sporcunun teknik-taktik becerilerin geliştirilerek ileri seviyeye çıkarılması, şut isabet performansında etkili olmaktadır, buna karşın teknik hatalar atış hızını ve isabeti olumsuz etkiler (Sevim, 1997). Üst düzey müsabakalarda teknik ve taktiksel becerilerin mi yoksa kas kuvveti ve gücünün mü daha önemli etkenler olduğu tartışılmaktadır (Cardoso Marques ve González-Badillo, 2006).

Sezon içinde teknik antrenmanların ve müsabakaların artması nedeniyle sezon boyunca yeterli güç ve kuvvet seviyelerini korumak için güç ve kondisyon çalışmaları önerilmektedir (Buchheit ve ark., 2008; Cardoso Marques ve González-Badillo, 2006). Hentbol oynamak kendi başına bu faktörlerin çoğunu artırabilse de, elit yarışmacılar yüksek şiddetli interval aerobik efor, hız, çeviklik, güç ve güç geliştirme egzersizleri içeren hentbola özgü kondisyona sahip olmalıdır (Buchheit ve ark., 2008; Cardoso Marques ve González-Badillo, 2006); maksimal koşu hızını ve sıçrama yüksekliğini iyileştirmek için hız ve patlayıcı kuvvet antrenmanının bir kombinasyonu, (Chelly ve ark., 2009; Christou ve ark., 2006) ve anaerobik güç ve patlayıcı kapasiteyi geliştirmek için yüksek şiddetli koşu drilleri (Buchheit ve ark., 2009, 2008) gerekir. Bununla birlikte, en uygun dozaj hakkında çok az şey bilinmektedir ve sezon içi yüksek dirençli çalışmaların spora özgü antrenman ile birleştirilmesi durumunda, antrenman programının birkaç bileşeninin birbiriyle etkileşime girebileceği konusunda endişeler devam etmektedir (Hermassi, Chelly, Tabka, Shephard, ve Chamari, 2011; Jensen, Jacobsen, Hetland, ve Tveit, 1997).

Hücum oyuncuları oyunun anlık durumuna göre genellikle 9, 10, 11 metrelerden sıçrayarak kale atışı yaparlar. Hentbol turnuvalarındaki $9 \mathrm{~m}$ atış isabet oranları incelendiğinde 2015 Dünya Şampiyonası'nda birincisi olan Fransa'nın \%46, ikinci olan Katar'ın \%58'dir. 2016 Avrupa Şampiyonası birincisi Almanya \%51 ile üçüncü olan Hırvatistan ise \%50 ile madalyaya ulaşmışlardır (European Championship Analyses, 2015). Bu verilerden de anlaşılacağı gibi sonucu belirleyici olan kimi zaman $9 \mathrm{~m}$ atış isabet oranı iken kimi zaman ise diğer etkenler olmuştur. 
$\mathrm{Bu}$ araştırmanın amacı, 19-24 yaş arası erkek hentbolcularda iki farklı antrenmanın $9 \mathrm{~m}$ atış isabet oranları ve bununla ilgili motorsal özellikler üzerine etkisini araştırmaktır. Hipotez olarak, hentbol oyununda teknik antrenmanın kuvvet antrenmanına göre kale atışlarında ve bunlar için gerekli olan bazı motor becerilerde olumlu etkilerinin daha iyi olabileceği düşünülmüştür.

\section{YÖNTEM}

\section{Çalışma Grubu}

Araştırmaya daha önce Manisa ili amatör spor kulüplerinde 3-5 yıl lisanslı sporculuk yapmış üniversite sporları federasyonunun düzenlemiş olduğu 1. lig klasmanında mücadele eden, Manisa Celal Bayar Üniversitesi Spor Bilimleri Fakültesi öğrencisi 30 hentbol sporcusu dahil edildi. Boy uzunluğu ölçümü; hassaslık derecesi $\pm 0.1 \mathrm{~cm}$ olan bir stadiometre (Charder Co. Ltd., HM200P, USA) ile, vücut ağırlığı; hassaslık derecesi $\pm 0.1 \mathrm{~kg}$ olan Tanita (TBF 300) kullanılarak kg cinsinden ölçüldü.

Bu çalışma için Dokuz Eylül Üniversitesi Girişimsel Olmayan Araştırmalar Etik Kurulu 19.11.2015 tarih ve 2365-GOA protokol numaral1 2015/26-17 karar numaralı onayıla yapıld1. Ayrıca çalışma öncesinde katılımcılar yazılı ve sözlü olarak bilgilendirildi ve katılımcıların yazılı onamları alındı. Manisa Celal Bayar Üniversitesi Spor Bilimleri Fakültesi’nde hizmet veren Sağlık için Spor Merkezi'nde kuvvet antrenmanları, Atatürk Spor Salonu'nda teknik antrenmanlar ve Performans Laboratuvarı'nda testler yapıldı.

\section{Testler}

Tüm katılımcılara yaptırılan ön testler ile $9 \mathrm{~m}$ atış isabetleri, dikey sıçrama yükseklikleri, 20 m sürat koşusu zamanları, öne sağlık topu firlatma mesafeleri, 30 sn şınav ve 30 sn mekik sayıları belirlendi. Testlerden önce alıştırma denemeleri yapıldı. Ön test sonuçlarına göre her iki tarafa eşit sayıda ve özelliklerde dağılımı sağlanacak şekilde 15'er kişilik teknik ve kuvvet antrenman grupları ( $\mathrm{n}=15$ x 2) oluşturuldu. Teknik Antrenman Grubunun (TAG) boy uzunluğu ortalaması $1.78 \pm 08 \mathrm{~m}$, vücut ağırlığı ortalamaları $78.7 \pm 9.59 \mathrm{~kg}$; Kuvvet Antrenman Grubunun (KAG) ise boy uzunluğu ortalaması $1.80 \pm 09$ m, vücut ağırlığı ortalamaları 76.66 \pm 13.47 kg idi. 12 hafta boyunca bir gruba kuvvet antrenmanları, diğerine ise teknik antrenmanlar uygulandı. İki gruba da belirlenen antrenmanların dışında başka bir ek antrenman yaptırılmadı. 12 haftadan sonra yapılan son testte aynı testler tekrarlandı. Testler aynı şartlar altında aynı kişiler tarafından aynı 
saatlerde (12:00 ile 13:30 arasında) yapıldı. Tüm testlerden önce aynı 1sınma prosedürü [(10 dakika genel ısınma +10 dakika topla ısınma (pas ve kale atışı)] uygulandı.

Kale Atışı (Şut İsabeti): Hentbolcuların şut isabet performansını değerlendirebilmek için kalenin belirlenen bölgelerine şut atışları yapmaları istendi. Hentbol kalesinin sağ-sol, alt ve üst köşelerine $50 \mathrm{~cm}$ x $50 \mathrm{~cm}$ genişliğinde dört adet fileli hedef alanları tespit edildi. Sporcu dört hedeften hangisini isterse ona atış yaptı. Hentbolculardan orta oyun kurucu mevkiinden $9 \mathrm{~m}$ atış çizgisini geçmeden hentbol normal üç adım kuralına uygun olarak dayanma adımlı, yüksek temel atış tekniğiyle hedeflere 10 adet şut çekmeleri istendi. Her bir atış sonrası 11 metre mesafedeki kasa içerisinde bulunan diğer toplar birer birer alınarak 10 atış tamamlandı. Bu test için iki kez deneme hakkı verildi, iki denemeden en iyisi test sonucu olarak değerlendirmeye alındı. Denemeler arasında $3 \mathrm{dk}$ dinlenme verildi. Bu çalışmada önceki benzer atış çeşitleri ile ilgili çalışmalarda ve maçlarda en çok kullanılan dayanma adımlı yüksek temel atış tekniği kullanıldı (Akan, 2006; E Çetin, 2009; Roland van den Tillaar ve Ettema, 2004). Tüm atış ve çalışmalarda MIKASA HBTS3 marka top kullanıldı.

Dikey Sıçrama: Sporcular duvar kenarında ayakta durdular. Pudraya bulaştırılmış parmakları ile kolunu gererek, duvarda uzanabildiği en üst noktaya temas ettiler. Bu evrede katılımcının ayak tabanlarının yerden temasının kesilmemesine ve kolun gergin olmasına dikkat edildi. Bu pozisyonda bütün güçleriyle sıçrayarak ve temas edebildikleri zirve noktayı işaretlediler. İki deneme hakkı verilerek en iyi sonuç değerlendirildi. İki nokta arasındaki mesafe katılımoının dikey sıçrama skoru olarak kaydedildi.

20 Metre Sürat Koşusu: Sporcular oyun sahasında 20 metre olarak işaretlenmiş alanda yüksek çıkış yaparak en yüksek hızda koştular. Sporculara 180 sn istirahat süresi verilerek iki deneme yapıldı, en iyi sonuç değerlendirildi. Skorlar CASIO marka kronometre ile kaydedildi.

Öne Sağlık Topu Fırlatma: Sporcular 1500 gr ağırlığındaki sağlık topunu oldukları yerden dominant kolu ile işaretlenen çizginin arkasından en yüksek güçlerini kullanarak firlattılar (Gençoğlu, 2008). Sporculara atışlar arası 60 sn dinlenme süresi verilerek 3 kez atış yaptırıldı. En iyi skor kaydedildi.

30 Saniye Şınav: Sporcular komutla şınav çekmeye başladılar. Gövde cephe pozisyonunda kollar bir omuz genişliğinde açık, göğüs yere temas edecek şekilde kollar bükülü pozisyonundan 
tekrar gövdenin yukarı kaldırdığı, dirseklerin tam gerginliğe ulaştığı hareket doğru olarak kabul edildi. 30 saniye boyunca en yüksek hızlarında şınav çektiler, en yüksek şınav sayısı kaydedildi.

30 Saniye Mekik: Sporculardan 30 sn süresince maksimal hızlarında mekik çekmeleri istendi. Sırtın yere teması ve gövdenin yukarı doğru doğrularak dirseklerin dize değmesi doğru hareket olarak kabul edildi. Skorlar adet olarak kaydedildi.

\section{Kuvvet Antrenman Programları}

Tablo 1'deki antrenman programları Pazartesi, Çarşamba ve Cuma günleri dönüşümlü olarak sırasıyla uygulanmıştır. Dayanma adımlı yüksek temel atış tekniğinde pectoralis major, deltoid, biceps, triceps, trapezius, latissimus dorsi, rectus abdominis, quadratus lumborum, quadriceps, hamstring kasları yoğun kullanıldığı için aşağıdaki hareketler seçildi.

Tablo 1. Kuvvet antrenman programları

\begin{tabular}{|c|c|c|c|c|c|c|}
\hline \multirow{2}{*}{\multicolumn{4}{|c|}{$\begin{array}{r}\text { Isınma: Koşu Bandi ile } \% \text { I egimde } 8 . \\
\text { 1. Program }\end{array}$}} & \multicolumn{3}{|c|}{ 2. Program } \\
\hline & & & Tekrar & Bölge & Hareket & Tekrar \\
\hline 1 & Göğüs & Chest Press & 15 & Sirt & Lat Pull Down & 15 \\
\hline 2 & Göğüs & Pec Deck Fly & 15 & Sirt & Seated Row & 15 \\
\hline 3 & Ön Kol & Dumbell Curl & 15 & Omuz & Shoulder Press & 15 \\
\hline 4 & Ön Kol & Dumbell Concentration & 15 & Bel & Hyperextension & Maksimal \\
\hline 5 & Bacak & Leg Curl & 15 & Bel & Twist & Maksimal \\
\hline 6 & Bacak & Leg Extension & 15 & Arka Kol & Dumbell Triceps Extension & 15 \\
\hline 7 & Karın & Incline Sit Ups & 15 & Arka Kol & Triceps Extension & 15 \\
\hline 8 & Karın & Abdominal Crunch & Maksimal & Karın & Sit Ups & Maksimal \\
\hline
\end{tabular}

Test öncesi uyum haftasında sporcuların en fazla $15 \pm 1$ tekrar yapabildikleri ağırlıklar tespit edildi. Antrenmanlarda setler ilk hafta 1'er set, 2. hafta 2'şer set, 3. haftadan itibaren 3'er set olarak uygulandı. Set arası dinlenme süreleri $1 \mathrm{dk}$, hareketler arası dinlenme süreleri ise $3 \mathrm{dk}$ uygulandı. Çalıştırılan kaslara hareket sonrası germe uygulandı. Antrenmandan sonra $5 \mathrm{dk}$ soğuma yürüyüşü ve strecthing yapıldı. 6 hafta sonunda 15 tekrar yapabildikleri ağırlıklar güncellendi. Tekrar sayısı "Maksimal" olarak gösterilen hareketler vücut ağırlığı ile yapılan hareketlerdi ve sporcular yapabildikleri en yüksek sayıyı yaptılar.

\section{Teknik Antrenman Programları}

Tablo 2'deki antrenman programları Pazartesi, Çarşamba ve Cuma günleri dönüşümlü olarak sırasıyla uygulanmıştır. 
Pilça, O., ve Altun, M. (2019). 12 Haftalık Hentbol Teknik ve Kuvvet Antrenmanının Atış ve Güç Performansı Üzerindeki Etkilerinin Değerlendirilmesi. CBÜ Beden Eğitimi ve Spor Bilimleri Dergisi, 14(1), 66-78.

Tablo 2. Teknik antrenman programları

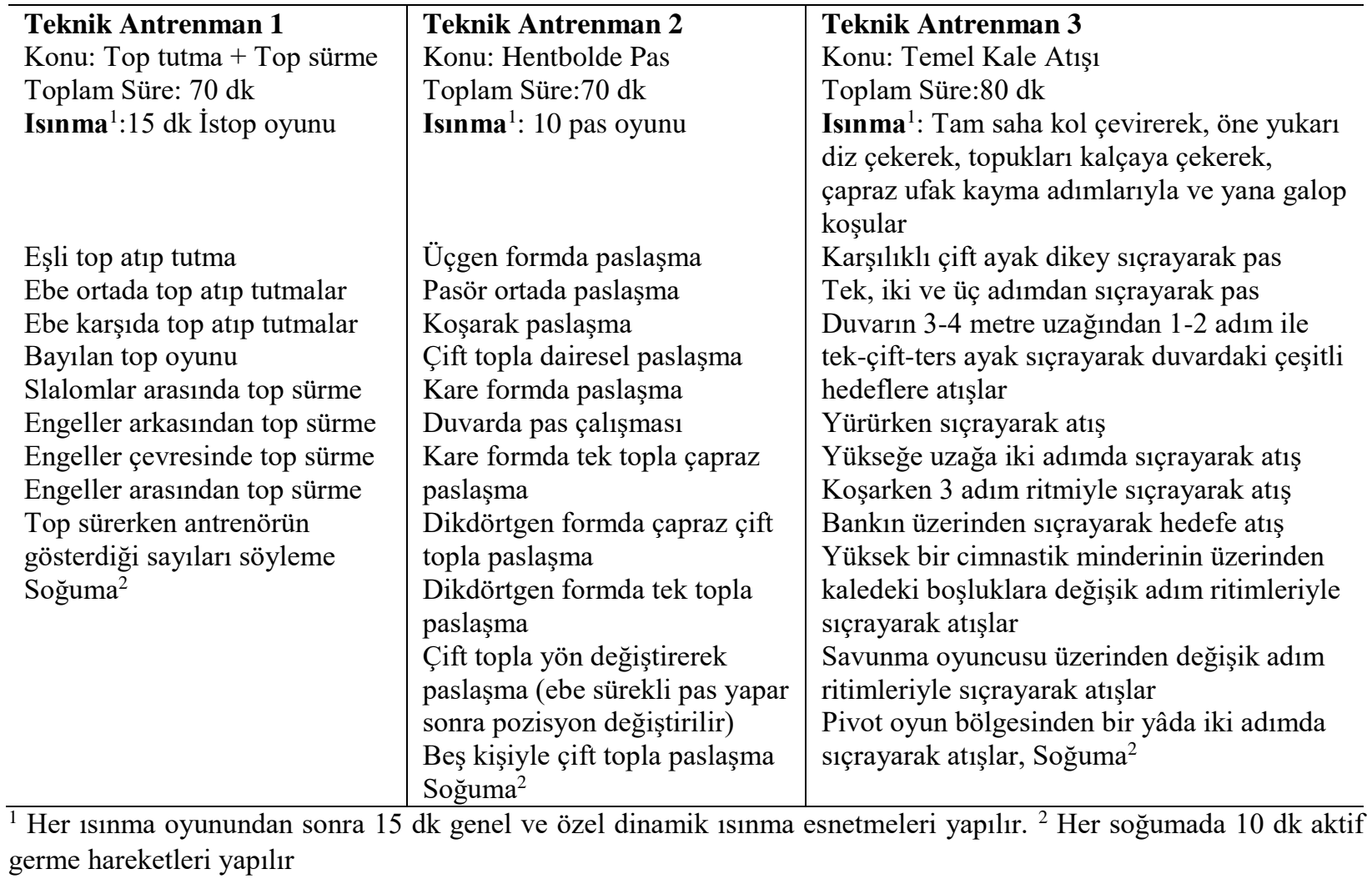

\section{Verilerin Analizi}

Çalışmada her bir gruptaki katılımcı sayısının 30'un altında olması sebebiyle Nonparametrik testler kullanıldı. Grup içi analizleri için Wilcoxon T analizi, iki grup arasındaki farklılıkları tespit etmek için ise Mann Whitney U analizi kullanıldı.

\section{BULGULAR}

12 hafta sonunda iki grubun da vücut ağırlıklarında anlamlı bir değişim olmadı.

Araştırmaya katılan TAG ve KAG'nin ön test ve son test ortalamaları, antrenman sonrasında öncesine göre oluşan değişiklikler Tablo 3'te verilmiştir. 
Pilça, O., ve Altun, M. (2019). 12 Haftalık Hentbol Teknik ve Kuvvet Antrenmanının Atış ve Güç Performansı Üzerindeki Etkilerinin Değerlendirilmesi. CBÜ Beden Eğitimi ve Spor Bilimleri Dergisi, 14(1), 66-78.

Tablo 3. Grupların antrenman sonrasında öncesine göre oluşan değişiklikler

\begin{tabular}{|c|c|c|c|c|c|c|c|c|}
\hline \multirow{2}{*}{ PARAMETRELER } & \multicolumn{4}{|c|}{ TAG $(n=15)$} & \multicolumn{4}{|c|}{ KAG (n=15) } \\
\hline & Ön Test & Son Test & Fark & $\mathbf{p}$ & Ön Test & Son Test & Fark & $\mathbf{p}$ \\
\hline $\begin{array}{l}\text { Kale Atış1 } \\
\text { (İsabet sayısı) }\end{array}$ & $\begin{array}{l}1.13 \\
\pm .83\end{array}$ & $\begin{array}{c}1.66 \\
\pm 1.04\end{array}$ & $\begin{array}{c}, 53 \\
\pm, 63\end{array}$ & $.011^{*}$ & $\begin{array}{l}1.06 \\
\pm .79\end{array}$ & $\begin{array}{c}1 \\
\pm .84\end{array}$ & $\begin{array}{l}-, 06 \\
\pm, 79\end{array}$ & .739 \\
\hline $\begin{array}{l}20 \mathrm{~m} \text { sürat } \\
\text { (sn.ss) }\end{array}$ & $\begin{array}{l}3.28 \\
\pm .24\end{array}$ & $\begin{array}{l}3.19 \\
\pm .18\end{array}$ & $\begin{array}{l}-.09 \\
\pm .12\end{array}$ & $.013 *$ & $\begin{array}{l}3.32 \\
\pm .29\end{array}$ & $\begin{array}{l}3.34 \\
\pm .29\end{array}$ & $\begin{array}{c}.01 \\
\pm .03\end{array}$ & .130 \\
\hline $\begin{array}{l}\text { Şınav } \\
\text { (30sn'deki sayı) }\end{array}$ & $\begin{array}{c}28 \\
\pm 9.11\end{array}$ & $\begin{array}{l}26.73 \\
\pm 7.97\end{array}$ & $\begin{array}{l}-1.26 \\
\pm 2.96\end{array}$ & .119 & $\begin{array}{l}33.86 \\
\pm 9.78\end{array}$ & $\begin{array}{c}35.2 \\
\pm 10.4\end{array}$ & $\begin{array}{c}1.33 \\
\pm 2.25\end{array}$ & $.028^{*}$ \\
\hline $\begin{array}{l}\text { Mekik } \\
\text { (30sn'deki say1) }\end{array}$ & $\begin{array}{l}29.26 \\
\pm 5.54\end{array}$ & $\begin{array}{l}30.06 \\
\pm 6.44\end{array}$ & $\begin{array}{c}.8 \\
\pm 4.17\end{array}$ & .673 & $\begin{array}{c}27.2 \\
\pm 4.78\end{array}$ & $\begin{array}{c}29 \\
\pm 6.04\end{array}$ & $\begin{array}{c}1.8 \\
\pm 1.93\end{array}$ & $.003 * *$ \\
\hline $\begin{array}{l}\text { Sağlık topu firlatma } \\
\text { (m) }\end{array}$ & $\begin{array}{l}14.55 \\
\pm 1.88\end{array}$ & $\begin{array}{l}14.79 \\
\pm 2.05\end{array}$ & $\begin{array}{l}.24 \\
\pm 2\end{array}$ & .209 & $\begin{array}{l}13.74 \\
\pm 2.1\end{array}$ & $\begin{array}{l}14.32 \\
\pm 2.26\end{array}$ & $\begin{array}{l}.57 \\
\pm .8\end{array}$ & $.002 * *$ \\
\hline $\begin{array}{l}\text { Dikey sıçrama } \\
(\mathrm{cm})\end{array}$ & $\begin{array}{l}48.86 \\
\pm 8.59\end{array}$ & $\begin{array}{c}51.6 \\
\pm 11.92\end{array}$ & $\begin{array}{c}2.73 \\
\pm 5.78\end{array}$ & $.030 *$ & $\begin{array}{c}50.6 \\
\pm 16.91\end{array}$ & $\begin{array}{c}50.06 \\
\pm 15.45\end{array}$ & $\begin{array}{l}-.53 \\
\pm 3.88\end{array}$ & .419 \\
\hline
\end{tabular}

*p $<0.05$ Ön Testten farklı; $* * \mathrm{p}<0.01$ Son Testten farkl1

$\mathrm{Bu}$ araştırmada uygulanan 12 haftalık kuvvet antrenmanları sonucunda kuvvet grubu hentbolcuların sağlık topu atma $(p<0.01), 30$ saniye şınav $(p<0.05)$, ve mekik $(p<0.01)$, derecelerinde gelişmeler meydana gelmiştir. 20 metre sürat ve şut performanslarında istatistiksel anlamlı derecede gelişim olmamıştır $(\mathrm{p}>0,05)$. Teknik grubun antrenmanlarının sonucunda oyuncularının şut isabet, $20 \mathrm{~m}$ sürat ve dikey sıçrama performanslarında anlamlı gelişme olduğu bulunmuştur $(\mathrm{p}<0.05)$.

Mann Whitney U test sonuçlarına göre gruplarda antrenmanla meydana gelen farklar gruplar arası karşılaştırılmış ve sonuçlar Tablo 4'de gösterilmiştir.

Tablo 4. Antrenmanla meydana gelen farkl11ıkların karşılaştırılması

\begin{tabular}{lccc}
\hline PARAMETRELER & TAG & KAG & p \\
\hline Kale Atışı (İsabet sayısı) & $.53 \pm .63$ & $-.06 \pm .79$ & $.028^{*}$ \\
20 m sürat koşusu (sn.ss) & $-.09 \pm .12$ & $.01 \pm .03$ & $.010^{*}$ \\
Şınav (30sn'deki sayı) & $-1.26 \pm 2.96$ & $1.33 \pm 2.25$ & $.005^{* *}$ \\
Mekik (30sn'deki sayı) & $.8 \pm 4.17$ & $1.8 \pm 1.93$ & $.038^{*}$ \\
Sağlık topu firlatma (m) & $.24 \pm 2$ & $.57 \pm .8$ & .901 \\
Dikey sıçrama (cm) & $2.73 \pm 5.78$ & $-.53 \pm 3.88$ & $.034^{*}$
\end{tabular}

${ }^{*} \mathrm{p}<0.05 ;{ }^{* *} \mathrm{p}<0.01$ TAG: Teknik Antrenman Grubu, KAG: Kuvvet Antrenmanı Grubu 
Tablo 4'te görüldüğü gibi kale atışı isabet oranı, 20 metre sürat koşu zamanı ve dikey sıçrama mesafesinde $\mathrm{p}<0.05$ düzeyinde TAG lehine pozitif farklılık saptanmıştır. Mekik $(\mathrm{p}<0.05)$ ve şınav sayısında $(\mathrm{p}<0.01)$ ise kuvvet grubu lehine anlamlı pozitif farkl11ık bulunmuştur.

\section{TARTIŞMA VE SONUÇ}

Çalışmanın bulgularına göre teknik antrenman grubunda kale atışı isabet oranı, 20 metre sürat koşu zamanı ve dikey sıçrama mesafesinde anlamlı gelişme olurken kuvvet antrenmanı grubunda ise 30 sn'deki şınav ve mekik sayısında anlamlı gelişmeler saptanmıştır. Sağlık topu firlatma mesafesi kuvvet antrenmanı grubunda daha iyi bulunmasına rağmen farklılık anlamlı düzeyde değildir.

$\mathrm{Bu}$ çalışmanın en önemli bulgusu $9 \mathrm{~m}$ kale atışı isabet sayısının 12 hafta sonunda sadece teknik antrenman grubunda gelişim sağlamasıdır. Hermassi ve ark., (2011) hentbol oyuncuları üzerinde yaptıkları araştırmada, 8 hafta boyunca oyunculara kuvvet antrenmanı uyguladılar ve aynı süre içerisinden kontrol grubunda bulunan hentbol oyuncuları mevcut antrenman programlarına devam ettirdiler. Bu çalışmanın bulgularını destekler biçimde, araştırmanın sonunda deney ve kontrol grubunda bulunan oyuncuların $9 \mathrm{~m}$ serbest atı̧ performanslarında anlamlı bir değişiklik meydana gelmediğini, bu sonucun ortaya çıkmasında $9 \mathrm{~m}$ atış performansının sporcuların teknik kapasiteleri ile yakından ilişkili olmasının etkili olduğunu rapor ettiler. Ayrica hem deney hem de kontrol grubunda bulunan oyuncuların antrenman programı içerisinde $9 \mathrm{~m}$ atış performansını ve tekniğini geliştirmeye yönelik özel çalışmalar yapmamalarının da bu sonucun ortaya çıkmasında etkili olduğu savundular. Hermassi ve ark., (2011) ve bu çalışmanın sonuçlarına göre farkın sebebi teknik antrenmanın etkisi gibi görünmektedir. Çünkü hentbolda teknik beceri düzeyini etkileyen birçok unsur bulunmakla beraber her oyuncunun atış tekniği de birbirinden farklı olabilmektedir. Literatürde yer alan benzer diğer araştırma sonuçları atış performansının sadece uygulanan antrenman modeline bağlı olarak değil, aynı zamanda sporcuların teknik beceri ve kognitif özelliklerine göre şekillendiği düşüncesini desteklemektedir (Ion, 2014; Loffing ve Hagemann, 2014; Marques, Saavedra, Abrantes ve Aidar, 2011). Marques ve ark., (2011) tarafından yapılan araştırmada sporcunun sahip olduğu kognitif becerilerin atış performansı üzerinde önemli bir belirleyici olduğu belirtilmiştir. 
Hentbol gibi atış hareketinin çok uygulandığı spor dallarında şut hızının önemli bir yere sahip olduğu ifade edilmektedir (Van Den Tillaar, 2004). Özellikle omuz internal ve external rotator kas gruplarının hentbolda atış hızı üzerinde önemli bir belirleyici olduğu bilinmektedir (Pontaga ve Zidens, 2014). Marques ve ark., (2011) tarafından yapılan araştırmada elit hentbol oyuncularında şut hızının sporcuların kuvvet düzeyleri ile yakından ilişkili olduğu tespit edilmiştir. Yapılan diğer bir araştırmada, elit hentbol oyuncularında maksimal dinamik kuvvetin atış hızını anlamlı düzeyde etkilediği sonucuna ulaşı1mıştır (Marques, van den Tilaar, Vescovi, ve GonzalezBadillo, 2007). Bu çalışmada şut hızı ölçülmemiş, sadece atış kuvveti ve hızından etkilenen sağlık topu firlatma mesafesi ölçülmüştür. Kuvvet antrenmanı grubunda bu gücün anlamsız oranda arttığı ancak atış performansına anlamlı katkısının olmadığı ortaya çıkmıştır. Akpınar ve Mirzeoğlu (2006) araştırmalarında hentbolcuların şut hızlarını etkileyen bazı kinematik unsurların bulunduğu, bunun yanında atış esnasında topun elden çıkma hızının hentbolcuların oynadıkları klasmanlara göre bazı farklılıklar gösterdiği belirlenmiştir. Çetin ve Balcı (2015) elit hentbol oyuncularının şut atma hızlarının düşük olduğu, buna karşılık şut isabet oranlarının yüksek olduğu tespit etmişlerdir. Chelly ve ark., (2010) yaptıkları bir araştırmada hem deney hem de kontrol grubunda bulunan hentbolcularda antrenmana paralel olarak şut isabet hızının artmamasının temelinde, şut isabet oranının sadece kuvvete bağlı bir olgu olmamasının yattığını belirtmişlerdir. Çetin ve Balcı (2015) hentbol oyuncularının üst ekstremite kuvvet düzeylerinin şut isabet oranı üzerinde herhangi bir anlamlı etkisinin olmadığı sonucunu bildirdiler. Bu çalışmada atış hızı ile ilgili bir ölçüm bulunmamakla beraber literatürdeki benzer araştırma bulguları değerlendirildiği zaman, hentbolda atış isabet oranının doğrudan şut hızı ile yakından ilişkili olmadığı ve çalışmamızın bulgularıyla paralel olarak kuvvet antrenmanının da atış isabet oranı üzerine etkisi olmadığı ortadadır.

$\mathrm{Bu}$ çalışmada kuvvet antrenmanlarıyla 30 sn mekik ve şınav sayılarında artı̧̧ meydana gelmiştir. Literatürde yer alan çeşitli araştırmalarda da sporcuların mevcut antrenman programlarına ek olarak yaptıkları kuvvet çalışmalarının kuvvet gelişimini desteklemeye yardımcı olduğu (Arazi ve Asadi, 2011; Ateş ve Ateşoğlu, 2007; Chelly, Ghenem ve ark., 2010; Ignjatovic, Markovic ve Radovanovic, 2012; Thomas French ve Hayes, 2009) ve bu nedenle branşa özgü antrenman modeli ile kuvvet antrenmanlarının kombine olarak birlikte yapılması gerektiği rapor edilmiştir (Christou, Smilios, Sotiropoulos, Volaklis, Pilianidis ve Tokmakidis, 2006). 
$\mathrm{Bu}$ çalışmada dikey sıçrama mesafesi TAG'de ön testte $48.86 \pm 8.59 \mathrm{~cm}$, son testte $51.6 \pm 11.92 \mathrm{~cm}$; KAG'de ön testte $50.6 \pm 16.91 \mathrm{~cm}$, son testte $50.06 \pm 15.45 \mathrm{~cm}$ bulunmuştur. Literatürde benzer çalışmalarda bundan biraz daha düşük (Chelly ve ark., 2010; Pantelis, Nikolaidis ve Ingebrigtsen, 2013; Souza, Gomes, Leme ve Silva, 2006), benzer (Yildırım ve Özdemir, 2010; Zorba, Göral ve Göral, 2014) ve biraz daha yüksek sonuçlar (Duyul Albay, Tutkun, Ağaoğlu, Canikli, 2008; Nikolaidis ve ark., 2016; Yıldırım ve Özdemir, 2010) vardır. Sonuçlar arasındaki önemli farklar güç platformu, sıçrama panosu gibi ölçüm aleti ve yöntemi farklarından kaynaklanmaktadır, elde edilen skorlar ortalama olarak uygun düzeydedir. Carvalho ve ark., (2014), uyguladıkları 12 haftalık kombine kuvvet ve plyometrik sıçrama alıştırmalarında Portekiz Hentbol Ligi üst seviye sporcuları ön test $38.68 \pm 8.12 \mathrm{~cm}$ dikey sıçrama değeri bulunurken, 12 haftalık çalışma sonrası $40.20 \pm 8.58 \mathrm{~cm}$ dikey sıçrama rapor edilmiştir (Carvalho, Mourão ve Abade, 2014). Bu çalışmada KAG'de bu kadar artış görülmezken, TAG'de artış olmuştur ve ölçülen dikey sıçrama sonuçları ile benzerlik göstermektedir.

Literatürde hentbol sporunda sürat mesafesi olarak çoğunlukla $20 \mathrm{~m}$ sprint koşuları kullanılmaktadır. Bu çalışmada 20 m sprint TAG'de ön testte $3.28 \pm .24$ sn, son testte $3.19 \pm .18$ sn; KAG'de ise ön testte $3.32 \pm .29$ sn, son testte $3.34 \pm .29$ sn bulunmuştur. TAG'de 12 hafta sonunda anlamlı iyileşme gözlemlenmiştir. Yapılan kuvvet antrenmanlarının \%60 şiddetinde kuvvette devamlılık tarzında yapılmasından dolayı KAG'de gelişim olmaması normaldir. TAG egzersizlerinde sıçrama ve sprint drillerinin fazlasıyla kullanılmasından dolayı anlamlı gelişme olduğunu düşünülmektedir. KAG egzersizleri daha yüksek şiddette patlayıcı kuvvet gelişimine yönelik olsaydı bu grupta da gelişim olabilirdi. Ayrıca seçilen hareketler dayanma adımlı yüksek atış tekniğine destek verecek türdeydi. Sprint performansına etki edecek hareketler kullanılmadı.

Bu çalışmada 30 saniye şınav ölçümlerinde TAG için ön testte $28 \pm 9.11$ adet, son testte $26.73 \pm 7.97$ adet, KAG için ön testte $33.86 \pm 9.78$ adet, son testte $35.2 \pm 10.4$ adet ölçülmüştür. Alıc1 ve İri'nin (2015) çalışmasında 13-15 yaş arasındaki hentbolcularda 30 sn şınav değerleri 27.27 \pm 6.96 adet olarak tespit edilmiştir. Ürer ve Kılınç (2014) 15-17 yaş grubu erkek hentbolculara yapmış olduğu çalışmasında araştırmaya katılan hentbolcular için ön test 30 saniye şınav ortalamasını $21.64 \pm 6.20$ adet, son test şınav değerini ortalama $26.0 \pm 5.49$ adet olarak tespit etmişlerdir. Her iki çalışma da bu çalışmanın bulguları ile tutarlıdır. 
Pilça, O., ve Altun, M. (2019). 12 Haftalık Hentbol Teknik ve Kuvvet Antrenmanının Atış ve Güç Performansı Üzerindeki Etkilerinin Değerlendirilmesi. CBÜ Beden Eğitimi ve Spor Bilimleri Dergisi, 14(1), 66-78.

$\mathrm{Bu}$ çalışmanın sınırlılıklarından biri sporcu sayısının az olmasıdır, ancak bir hentbol takımının sayısı ortalama bu kadardır. Daha büyük bir örneklem grubuyla çalışılsaydı bulunan sonuç daha anlamlı olabilirdi. Diğer bir sınırlılık ise daha yeni ve kapsamlı ölçüm aletleri kullanamamaktı. Bu çalışma sezon başı, sezon ortası ve sezon sonu olmak üzere farklı zaman dilimleri içinde tüm sezonu değerlendirerek yapılabilir. Farklı cinsiyetler ile çalışılabilir ve cinsiyetler karşılaştırılabilirdi. Ayrıca daha farklı mesafelerden atışlar uygulanarak yapılabilirdi.

Sonuç olarak, çalışma bulgularımıza dayanarak hentbol oyununda çok önemli olan $20 \mathrm{~m}$ sprint süratini, dikey sıçrama mesafesini ve $9 \mathrm{~m}$ atış isabetini geliştirmek için özellikle teknik çalışmalarından faydalanılması gerektiğini önermekteyiz. Bunun yanı sıra atış hızı ve kuvveti ile büyük ilgisi bulunan mekik, şınav ve sağlık topu atışlarının özellikle sezon başında yüksek şiddette, patlayıcı kuvvet antrenmanlarıyla geliştirilmesi, sezon içinde korunması göz önünde bulundurulmalıdır. Bu çalışmadaki gibi düşük şiddette çok tekrar ile uygulanırsa yeterli bir gelişim sağlamayacağı unutulmamalıdır.

\section{KAYNAKLAR}

Akan, İ. (2006). Hentbolde İsabetli Kale Atışlarında Submaksimal Atış Hızı ve Atış Kuvvetinin Biyomekanik Analizi. İstanbul: Marmara Üniversitesi Spor Bilimleri YL Tezi.

Akpınar, S. ve Mirzeoğlu, N. (2006). Farklı Düzeylerdeki Hentbol Oyuncularının Temel Atışlarının Kinematik Analizi. Spormetre Beden Eğitimi ve Spor Bilimleri Dergisi, 4(1), 19-23.

Alıcı, Ö., ve İri, R. (2015). Comparison of some physical and physiological characteristics of the male sedentaries, male handball players and male wrestlers whose ages were between 13 and $1513-15$ yaş arasındaki güreşçiler hentbolcular ve sedanterlerin baz1 fiziksel ve fizyolojik. International Journal of Human Sciences, 12(1), $1070-1081$. https://doi.org/10.14687/ijhs.v12i1.3117.

Arazi, H. ve Asadi, A. (2011). The Effect of Aquatic and Land Plyometric Training on Strength, Sprint, and Balance in Young Basketball Players. Journal of Human Sport ve Exercise, 6(1), 101-111.

Ateş, M. ve Ateşoğlu, U. (2007). Pliometrik Antrenmanın 16-18 Yaş Grubu Erkek Futbolcuların Üst ve Alt Ekstremite Kuvvet Parametreleri Üzerine Etkisi. SPORMETRE Beden Eğitimi ve Spor Bilimleri Dergisi, 1, 21-28.

Baumberger, J. (1992). Hentbol Oynayarak Öğrenme, Daha İyi Oynama. (H. 1998 Çoknaz, Ed.) (1. bask1). Ankara: Bagırgan Yayınevi.

Buchheit, M., Laursen, P., Kuhnle, J., Ruch, D., Renaud, C., ve Ahmaidi, S. (2009). Game-based Training in Young Elite Handball Players. International Journal of Sports Medicine, 30(04), 251-258. https://doi.org/10.1055/s-0028-1105943.

Buchheit, M., Millet, G. P., Parisy, A., Pourchez, S., Laursen, P. B., ve Ahmaidi, S. (2008). Supramaximal Training and Postexercise Parasympathetic Reactivation in Adolescents. Medicine ve Science in Sports ve Exercise, 40(2), $362-371$. https://doi.org/10.1249/mss.0b013e31815aa2ee.

Cardoso Marques, M. A., ve González-Badillo, J. J. (2006). In-Season Resistance Training and Detraining in Professional Team Handball Players. The Journal of Strength and Conditioning Research, 20(3), 563. https://doi.org/10.1519/R-17365.1. 
Pilça, O., ve Altun, M. (2019). 12 Haftalık Hentbol Teknik ve Kuvvet Antrenmanının Atış ve Güç Performansı Üzerindeki Etkilerinin Değerlendirilmesi. CBÜ Beden Eğitimi ve Spor Bilimleri Dergisi, 14(1), 66-78.

Carvalho, A., Mourão, P., ve Abade, E. (2014). Effects of Strength Training Combined with Specific Plyometric exercises on body composition, vertical jump height and lower limb strength development in elite male handball players: a case study. Journal of Human Kinetics, 41(1), 125-132. https://doi.org/10.2478/hukin-2014-0040.

Çetin, E. (2009). Hentbolda Temel Atış Hareketinin Kinematik Analizi. Antalya: Akdeniz Üniversitesi Doktora Tezi.

Çetin, E., ve Balcı, N. (2015). The Effects of Isokinetic Performance on Accurate Throwing in Team Handball. Procedia - Social and Behavioral Sciences, 174, 1872-1877. https://doi.org/10.1016/j.sbspro.2015.01.850.

Chelly, M. S., Fathloun, M., Cherif, N., Amar, M. Ben, Tabka, Z., ve Van Praagh, E. (2009). Effects of a back squat training program on leg power,jump, and sprint performances in junior soccer players. Journal of Strength and Conditioning Research. https://doi.org/10.1519/JSC.0b013e3181b86c40.

Chelly, M. S., Ghenem, M. A., Abid, K., Hermassi, S., Tabka, Z., ve Shephard, R. J. (2010). Effects of in-Season Short-Term Plyometric Training Program on Leg Power, Jump- and Sprint Performance of Soccer Players. Journal of Strength and Conditioning Research, 24(10), 2670-2676. https://doi.org/10.1519/JSC.0b013e3181e2728f.

Chelly, M. S., Hermassi, S., ve Shephard, R. J. (2010). Relationships between Power and Strength of the Upper and Lower Limb Muscles and Throwing Velocity in Male Handball Players. Journal of Strength and Conditioning Research, 24(6), 14801487. https://doi.org/10.1519/JSC.0b013e3181d32fbf.

Christou, M., Smilios, I., Sotiropoulos, K., Volaklis, K., Pilianidis, T. ve Tokmakidis, S. P. (2006). Effects of Resistance Training on The Physical Capacities of Adolescent Soccer Players. The Journal of Strength ve Conditioning Research, 20(4), 783791.

Christou, M., Smilios, I., Sotiropoulos, K., Volaklis, K., Pilianidis, T., ve Tokmakidis, S. P. (2006). Effects of Resistance Training on the Physical Capacities of Adolescent Soccer Players. The Journal of Strength and Conditioning Research, $20(4), 783$. https://doi.org/10.1519/R-17254.1.

Duyul Albay M., Tutkun E., Ağaoğlu Y.S., ve Canikli A., A. F. (2008). Hentbol, Voleybol ve Futbol Üniversite Takımlarının Bazı Motorik ve Antropometrik Özelliklerinin İncelenmesi. Spormetre Beden Eğitimi ve Spor Bilimleri Dergisi, VI(1), 13-20.

European Championship analyses. (2015). Avrupa Hentbol Federasyonu Web Sitesi. Tarihinde 13 Ağustos 2018, adresinden erişildi http://activities.eurohandball.com/analyses.

Gençoğlu, C. (2008). Hentbolcularda Üst Ekstremiteye Uygulanan Pliyometrik Egzersizin Atış Hızı ve İzokinetik Kas Kuvvetine Etkisi. İzmir: Dokuz Eylül Üniversitesi Doktora Tezi.

Gorostiaga, E. M., Granados, C., Ibanez, J., Gonzalez-Badillo, J. J., ve Izquierdo, M. (2006). Effects of an Entire Season on Physical Fitness Changes in Elite Male Handball Players. Medicine ve Science in Sports ve Exercise, 38(2), 357-366. https://doi.org/10.1249/01.mss.0000184586.74398.03.

Hermassi, S., Chelly, M. S., Tabka, Z., Shephard, R. J., ve Chamari, K. (2011). Effects of 8-Week in-Season Upper and Lower Limb Heavy Resistance Training on The Peak Power, Throwing Velocity, and Sprint Performance of Elite Male Handball Players. Journal of Strength and Conditioning Research, 25(9), 2424-2433. https://doi.org/10.1519/JSC.0b013e3182030edb.

Ignjatovic, A. M., Markovic, Z. M., ve Radovanovic, D. S. (2012). Effects of 12-Week Medicine Ball Training on Muscle Strength and Power in Young Female Handball Players. Journal of Strength and Conditioning Research, 26(8), $2166-2173$. https://doi.org/10.1519/JSC.0b013e31823c477e.

Ion, M. (2014). Technical Training Methods for Increasing the Junior Handball Teams. Procedia - Social and Behavioral Sciences, 116, 2004-2009. https://doi.org/10.1016/j.sbspro.2014.01.511.

Jensen, J., Jacobsen, S., Hetland, S., ve Tveit, P. (1997). Effect of Combined Endurance, Strength and Sprint Training on Maximal Oxygen Uptake, Isometric Strength and Sprint Performance in Female Elite Handball Players During a Season. International Journal of Sports Medicine, 18(05), 354-358. https://doi.org/10.1055/s-2007-972645.

Loffing, F., ve Hagemann, N. (2014). Skill differences in visual anticipation of type of throw in team-handball penalties. Psychology of Sport and Exercise, 15(3), 260-267. https://doi.org/10.1016/j.psychsport.2014.01.006.

Marques, M., Saavedra, F., Abrantes, C. ve Aidar, F. (2011). Associations Between Rate of Force Development Metrics and 
Pilça, O., ve Altun, M. (2019). 12 Haftalık Hentbol Teknik ve Kuvvet Antrenmanının Atış ve Güç Performansı Üzerindeki Etkilerinin Değerlendirilmesi. CBÜ Beden Eğitimi ve Spor Bilimleri Dergisi, 14(1), 66-78.

Throwing Velocity in Elite Team Handball Players: a Short Research Report. Journal of Human Kinetics, 53-57.

Marques, M. C., van den Tilaar, R., Vescovi, J. D., ve Gonzalez-Badillo, J. J. (2007). Relationship between throwing velocity, muscle power, and bar velocity during bench press in elite handball players. International journal of sports physiology and performance, 2(4), 414-422. https://doi.org/10.1123/ijspp.2.4.414.

Nikolaidis, P. T., ve Ingebrigtsen, J. (2013). Physical and Physiological Characteristics of Elite Male Handball Players from Teams with a Different Ranking. Journal of Human Kinetics, 38, 115-124. https://doi.org/10.2478/hukin-2013-0051.

Nikolaidis, P. T., Torres-Luque, G., Chtourou, H., Clemente-Suarez, V. J., Ramírez-Vélez, R., ve Heller, J. (2016). Comparison between jumping vs. cycling tests of short-term power in elite male handball players: the effect of age. Movement ve Sport Sciences - Science ve Motricité, (91), 93-101. https://doi.org/10.1051/sm/2015046.

Pontaga, I. ve Zidens, J. (2014). Shoulder Rotator Muscle Dynamometry Characteristics: Side Asymmetry and Correlations with Ball-Throwing Speed in Adolescent Handball Players. Journal of Human Kinetics, 42, 41-50.

Sevim, Y. (1997). Hentbol teknik-taktik (1. bask1). Ankara: Tutibay Ltd.Şti.

Souza, J. de, Gomes, A. C., Leme, L., ve Silva, S. G. da. (2006). [Changes in metabolic and motor performance variables induced by training in handball players] Alterações em variáveis motoras e metabólicas induzidas pelo treinamento durante um macrociclo em jogadores de handebol. Revista Brasileira de Medicina do Esporte, 12(3), $129-134$. https://doi.org/10.1590/S1517-86922006000300004.

Thomas, K., French, D. ve Hayes, P. R. (2009). The Effect of Two Plyometric Training Techniques on Muscular Power and Agility in Youth Soccer Players. The Journal of Strength ve Conditioning Research, 23(1), 332-335.

Ürer, S., ve Kılınç, F. (2014). 15-17 yaş grubu erkek hentbolculara üst ve ekstremiteye yönelik uygulanan pliometrik antrenmanların dikey sıçrama performansına ve blok üstü şut atışı isabetlilik oranına etkisinin araştırılması. Inönü Üniversitesi Beden Ĕgitimi ve Spor Bilimleri Dergisi, 1(2), 16-38.

Van Den Tillaar, R. (2004). Effect Of Different Training Programs on the Velocity of Overarm Throwing: A Brief Review. The Journal of Strength ve Conditioning Research, 18(2), 388-396.

van den Tillaar, R., ve Ettema, G. (2004). A force-velocity relationship and coordination patterns in overarm throwing. Journal of sports science ve medicine, 3(4), 211-219. Tarihinde adresinden erişildi https://www.ncbi.nlm.nih.gov/pmc/articles/PMC3938059/.

Yıldırım, İ. ve Özdemir, V. (2010). Elit Düzey Erkek Hentbol Oyuncularının Antropometrik Özelliklerinin İncelenmesi. Journal of Sports and Performance Researches, 1-1, 6-13.

Zorba, E., Göral, K., ve Göral, Ş. (2014). Elit Hentbolcularda Bazı Fiziksel Uygunluk Parametreleri Arasındaki İlişkilerin İncelenmesi. International journal of Science Culture and Sport, 2(5), 68-68. https://doi.org/10.14486/IJSCS75. 